\title{
Prevalence of atrial fibrillation in the Malaysian communities
}

\author{
Chiao Wen Lim, ${ }^{1}$ Sazzli Kasim, ${ }^{1}$ Johan Rizwal Ismail, ${ }^{1}$ Nicholas Yul Chye Chua, \\ Rizmy Najme Khir, ${ }^{1}$ Hafisyatul Aiza Zainal Abidin, ${ }^{1}$ Effarezan Abdul Rahman, ${ }^{1}$ \\ Mohd Kamal Mohd Arshad, ${ }^{1}$ Zubin Ibrahim Othman, ${ }^{1}$ Khalid Yusoff ${ }^{1,2}$
}

\begin{abstract}
${ }^{1}$ Faculty of Medicine, Universit Teknologi MARA, Sungai Buloh, Selangor, Malaysia ${ }^{2}$ UCSI University, Kuala Lumpur, Wilayah Persekutuan, Malaysia
\end{abstract}

\section{Correspondence to}

Dr Chiao Wen Lim, Faculty of Medicine, Universiti Teknologi MARA, Sungai Buloh, Selangor 47000, Malaysia; chiaowen.lim@gmail.com

Received 4 May 2016 Revised 1 November 2016 Accepted 4 November 2016

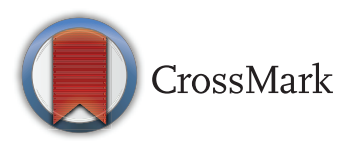

To cite: Lim CW, Kasim S, Ismail JR, et al. Heart Asia 2016:8:62-66.

doi:10.1136/heartasia-2016010775

\section{ABSTRACT}

Background and aim Atrial fibrillation (AF) is the most common sustained cardiac arrhythmia encountered in clinical practice. The REDISCOVER (Responding to Increasing Cardiovascular disease prevalence) study is an observational longitudinal community-based study that tracks changing lifestyles, risk factors and chronic disease in urban and rural areas of Malaysia. In this study, we aim to study the prevalence of $\mathrm{AF}$ and its associated risk factors.

Methods The study was conducted between 2007 and 2014. Participants were required to complete questionnaires on cardiovascular risk factors and medical history, and undergo physical examinations, blood tests, ECG and echocardiography examinations. Demographic variables including weight, height, blood pressure, serum glucose and serum lipid were recorded. Participants with AF were identified from their baseline ECG and at 3-year follow up.

Results A total of 10805 subjects participated in the study. Mean age was $52.6( \pm 11.6)$ years and $56 \%$ were female; $4.4 \%$ of subjects had a diagnosis of ischaemic heart disease, $1.3 \%$ had a previous stroke, $16.7 \%$ had diabetes mellitus and $45.6 \%$ had hypertension. There were 53 subjects diagnosed with AF at baseline, giving a prevalence of $0.49 \%$, and $0.54 \%$ at 3 years. AF was more prevalent in males $(58.5 \%$ in the $\mathrm{AF}$ group compared to $43.9 \%$ in sinus rhythm (SR) subjects; $\mathrm{p}=0.03$ ) and the older age group. Ischaemic heart disease was more prevalent in AF subjects (22.6\%) compared to SR subjects $(4.4 \%)(p<0.001)$. In the AF group previous stroke had occurred in $1.9 \%$ of subjects compared to $1.3 \%$ in the SR population ( $p=0.51$ ), and $24.5 \%$ of subjects in the AF group had diabetes compared to $16.6 \%$ in the SR group ( $p=0.12$ ). There was a significant difference in the prevalence of hypertension between the AF group (59.6\%) compared to the SR subjects $(45.5 \%)(p=0.04)$.

Conclusions The prevalence of $\mathrm{AF}$ in the Malaysian population was low at $0.54 \%$ compared to the global average of $1 \%$. We found that AF was associated with older age, male sex, hypertension, and ischaemic heart disease.

\section{BACKGROUND}

Atrial fibrillation (AF) is the most common sustained arrhythmia encountered in clinical practice. The prevalence of AF was estimated globally at 33.5 million in 2010, and will continue to rise with increasing age, increasing health care awareness and improving diagnostic tools. ${ }^{1}$ As AF has strong associations with cardiovascular diseases such as coronary artery disease, valvular heart disease, heart failure and hypertension, it will inevitably generate a substantial burden on the future cost of healthcare.

The prevalence and incidence of $\mathrm{AF}$ is well studied in the USA and Europe. Elsewhere, data on AF remains limited. Prevalence rates differ greatly between studies as well as regions. In the USA, the landmark Framingham Study found the prevalence of AF between the years 1968 and 1989 in a cohort aged 65-84 years to increase over time in men but not in women. ${ }^{2}$ In the ATRIA study, the overall prevalence was $0.95 \%$, with prevalence increasing from $0.1 \%$ among adults $<55$ years to $9.0 \%$ in those aged $\geq 80$ years. $^{3}$

In the UK, the overall prevalence of AF reported by the ECHOES study was $2 \%$, with prevalence rates of $1.6 \%$ in women and $2.4 \%$ in men. ${ }^{4}$ The Renfrew/Paisley study, which is one of the largest epidemiological studies with a cohort of 15 406, found an $\mathrm{AF}$ prevalence of $0.65 \%$ in the West of Scotland population. ${ }^{5}$ In Europe, the Rotterdam Study reported an overall prevalence of $5.5 \%$, with age adjusted prevalence rising from $0.7 \%$ in those aged $55-59$ years to $17.8 \%$ in those 85 years and older. ${ }^{6}$ Meanwhile, an Australian study estimated the prevalence of $\mathrm{AF}$ in adults aged $\geq 55$ years at $5.35 \%{ }^{7}$

In the Asia Pacific region, most AF studies have been conducted in Japan, Taiwan and China, with little data available from South East Asia. In Japan, numerous epidemiological studies in the 1990s2000s reported a consistent $\mathrm{AF}$ prevalence rate ranging from $0.6 \%$ to $1.6 \% .^{8-16}$ In Korea, in a study with a cohort of 14540 adults, Jeong ${ }^{17}$ reported an overall AF prevalence of $0.7 \%$ in adults $>40$ years of age and $2.1 \%$ in those $>65$ years. In China, four large community based studies published from 2008 to 2010 reported an AF prevalence ranging from $0.8-2.8 \% .^{18-21}$

To date, there have been only four published studies on AF prevalence in the community in South East Asia. The Thai community based studies reported differing prevalence from $0.4-2.2 \%{ }^{22} 23$ while Yap et $a l^{24}$ in Singapore reported a prevalence of $1.5 \%$ in the Chinese community aged $\geq 55$ years. There have been two AF studies in Malaysia: one community based study by Wong et $a l^{25}$ reported an AF prevalence of $0.75 \%$ in the 
hypertensive Sarawak population with no prevalence difference between gender; another study reported an AF prevalence of $2.8 \%$ in acute medical admissions to a single centre. ${ }^{26}$

A large scale community-based study on the prevalence of AF has never been carried out in a multiracial country such as Malaysia. Being a growing nation with a current population of 30 million, it is important to determine the prevalence of $\mathrm{AF}$ and its associated risk factors in the Malaysian cohort in order to project and estimate future healthcare cost implications from the rising prevalence of AF.

\section{METHODS}

The REDISCOVER (Responding to Increasing Cardiovascular disease prevalence) study is a longitudinal epidemiological study that was initiated by Universiti Teknologi MARA (UiTM) in the year 2007 with funding from the Ministry of Higher Education and Ministry of Science, Technology and Innovation Malaysia. It is an ongoing prospective community-based study which spans a period of 15 years, with a 3-yearly follow-up. Subjects recruited into the study included adults aged $\geq 30$ years from 18 urban and 22 rural communities across Malaysia. Figure 1 shows the map of the REDISCOVER study sites. The methodology of the sampling process and recruitment has been previously described. ${ }^{27}$ The institutional ethics committee approved the study protocol.

\section{Study population}

Participants recruited into this study were from five states in Malaysia to ensure adequate representation of the major ethnic groups. A standardised method of recruitment was adopted, in which announcements and invitations were made through local community leaders. All household members above 30 years of age residing in each locality were invited via written invitation to attend a screening session at their local community centres. Participants were requested to fast before screening. Overall, a response rate of $60-70 \%$ was recorded. All interviewers and investigators were trained regarding the study procedures before conducting the study. Standardised, interviewer-based questionnaires were used to collect information regarding age, gender, ethnicity and educational attainment. ${ }^{27}$ Questions asked in the questionnaires (which were in English and Malay) included cardiovascular risk factors, past medical history, drug history, social history, physical activities and dietary history.

Anthropometric measurements included height, weight, waist circumference and blood pressure. Blood pressure was measured twice after a 5 min rest using an automatic digital blood pressure monitor (Omron HEM 757) with a standard adult size cuff. ECG was recorded on a standard 12-lead format and calibrated

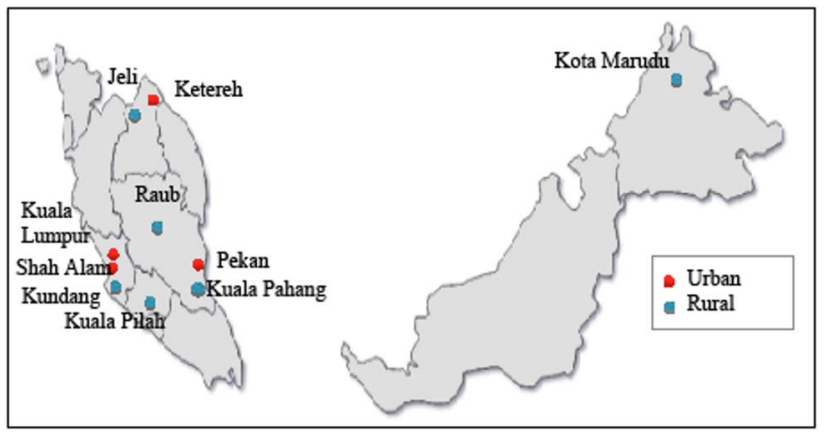

Figure 1 REDISCOVER (Responding to /ncreasing Cardiovascular disease prevalence) site map. with GE Marquette MAC 5000, while echocardiography examinations were performed using GE model Vivid I and Philips CX 5000 .

Fasting venous blood samples were collected for plasma glucose, plasma lipid and haemoglobin A1c and analysed with an automated enzymatic method. The participants were re-examined in two follow-up rounds. The first examination round was performed between July 2007 and December 2011. Follow-up data are currently being collected every 3 years for a period of 15 years. Hypercholesterolaemia was defined as fasting total plasma cholesterol $\geq 5.2 \mathrm{mmol} / \mathrm{L}$ and diabetes was diagnosed when fasting glucose was $\geq 7.0 \mathrm{mmol} / \mathrm{L}$. Hypertension was defined as mean blood pressure $\geq 140$ / $90 \mathrm{~mm} \mathrm{Hg}$ or if the subjects were on antihypertensive medications or were aware of being hypertensive.

\section{Evaluation of AF}

Initial screenings of all ECGs were done by clinicians who attended the recruitments and follow-ups. The diagnosis of AF was made retrospectively based on baseline screening 12-lead surface ECG. To verify the diagnosis of AF, all ECGs with a diagnosis of AF or atrial flutter or any other rhythm disorder were analysed independently by two cardiologists. Other ECG abnormalities indicative of prior myocardial infarction, ischaemia and left ventricular hypertrophy were also identified.

\section{Statistical analysis}

All data were analysed using SPSS (V.22; SPSS, IBM, Chicago, Illinois, USA). All parametric or normally distributed data were reported as mean (SD) and comparison of the means were performed using t-test. Categorical variables were described with frequency and percentage. Age-adjusted prevalence was computed using direct standardisation method. Significance level was set at $\mathrm{p}<0.05$.

\section{RESULTS}

A total of 12701 subjects were recruited. The population for analysis consisted of 10805 participants for whom a baseline ECG was available. In this population, which had a female predominance of 56\% (6048), prevalence at baseline and at first follow-up was measured.

The baseline characteristics of our study cohort are presented in table 1. There was a Malay ethnic predominance of $71.9 \%$, Chinese ethnicity of $10.7 \%$, Indian ethnicity of $2.9 \%$ and other ethnicities of $14.5 \%$; 5565 subjects lived in the urban areas while 5240 came from rural parts of Malaysia. Of this population cohort, $16.7 \%$ were diagnosed with diabetes mellitus, $45.6 \%$ with hypertension and $68.1 \%$ with hypercholesterolaemia. Only a small percentage reported as having ischaemic heart disease and stroke in the interview-based questionnaires (4.4\% and $1.3 \%$, respectively).

\section{Prevalence of AF}

Analysis of ECG data from our cohort of 10805 found 53 documented cases of $\mathrm{AF}$ at baseline, giving an overall prevalence of $0.49 \%$. At the third year follow-up, there were eight new cases of AF; however, three deaths were recorded in the AF cohort. The overall prevalence of $\mathrm{AF}$ at the third year was $0.54 \%$. There is an increasing trend of AF prevalence with age, which concurs with worldwide data on the prevalence of AF. The prevalence for those $<45$ years old was $0.14 \%$, those between $45-54$ was $0.09 \%$, rising to $0.64 \%$ in the age group $55-64$, and increasing steeply to $2.03 \%$ in those between 65 
Table 1 Baseline characteristics of subjects participating in the REDISCOVER study

\begin{tabular}{|c|c|c|c|c|}
\hline $\begin{array}{l}\text { Baseline } \\
\text { characteristics }\end{array}$ & $\begin{array}{l}\text { Total cohort } \\
\text { Mean }\end{array}$ & $\begin{array}{l}\text { AF cohort } \\
n=53\end{array}$ & $\begin{array}{l}\text { Sinus rhythm } \\
\text { cohort } \\
n=10752\end{array}$ & p Value \\
\hline Age (years) & $52.6( \pm 11.6)$ & $64.5( \pm 10.4)$ & $52.5( \pm 11.6)$ & $<0.001$ \\
\hline Weight $(\mathrm{kg})$ & $64.12( \pm 13.8)$ & $62.08( \pm 15.84)$ & $64.14( \pm 13.8)$ & 0.32 \\
\hline Height (m) & $1.57( \pm 0.08)$ & $1.56( \pm 0.10)$ & $1.57( \pm 0.09)$ & 0.79 \\
\hline $\begin{array}{l}\text { Body mass index } \\
\left(\mathrm{kg} / \mathrm{m}^{2}\right)\end{array}$ & $25.98( \pm 4.88)$ & $25.30( \pm 5.65)$ & $25.99( \pm 4.88)$ & 0.21 \\
\hline $\begin{array}{l}\text { Systolic BP } \\
(\mathrm{mm} \mathrm{Hg})\end{array}$ & $136.1( \pm 22.8)$ & $139.0( \pm 25.8)$ & $136.1( \pm 22.7)$ & 0.59 \\
\hline $\begin{array}{l}\text { Diastolic BP } \\
(\mathrm{mm} \mathrm{Hg})\end{array}$ & $80.4( \pm 12.1)$ & $83.0( \pm 15.77)$ & $80.4( \pm 12.1)$ & 0.20 \\
\hline $\begin{array}{l}\text { Serum glucose } \\
(\mathrm{mmol} / \mathrm{L})\end{array}$ & $5.7( \pm 2.37)$ & $5.68( \pm 2.09)$ & $5.70( \pm 2.37)$ & 0.85 \\
\hline $\begin{array}{l}\text { Total cholesterol } \\
(\mathrm{mmol} / \mathrm{L})\end{array}$ & $5.7( \pm 1.2)$ & $5.38( \pm 1.06)$ & $5.70( \pm 1.2)$ & 0.029 \\
\hline $\begin{array}{l}\text { Triglycerides } \\
\text { (mmol/L) }\end{array}$ & $1.75( \pm 1.04)$ & $1.70( \pm 0.92)$ & $1.75( \pm 1.04)$ & 0.41 \\
\hline $\begin{array}{l}\text { LDL cholesterol } \\
\text { (mmol/L) }\end{array}$ & $3.67( \pm 1.06)$ & $3.29( \pm 1.03)$ & $3.67( \pm 1.07)$ & 0.025 \\
\hline $\begin{array}{l}\text { HDL cholesterol } \\
(\mathrm{mmol} / \mathrm{L})\end{array}$ & $1.25( \pm 0.35)$ & $1.30( \pm 0.44)$ & $1.25( \pm 0.35)$ & 0.66 \\
\hline
\end{tabular}

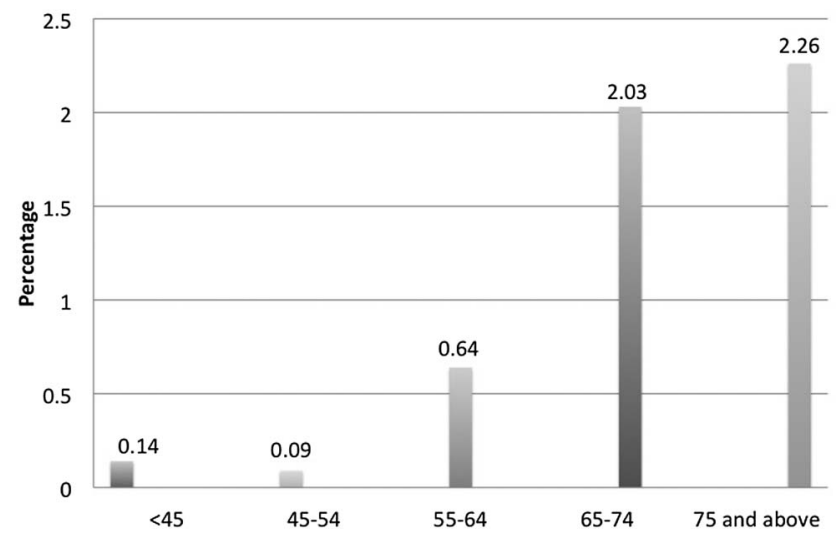

Figure 2 Prevalence of atrial fibrillation according to age group (years).

and 74 years old. There were a total of eight AF cases screened in the $\geq 75$ age group, giving a prevalence of $2.26 \%$ (figure 2 ).

In our cohort, AF prevalence was higher among males $(p=0.03)$ as shown in table 2 . However, there was no significant difference between ethnicity or urbanisation. Ischaemic heart disease was more prevalent in the AF cohort (22.6\%) compared to the subjects in sinus rhythm (SR) $(4.4 \%)(p<0.001)$. There was also a significant difference in hypertension in the AF group $(59.6 \%)$ compared to the SR subjects $(45.5 \%)(p=0.04)$. In the AF group, the prevalence for previous stroke was $1.9 \%$ compared to $1.3 \%$ in the SR population $(p=0.51)$. There was no significant difference in the prevalence of diabetes between the two cohorts. In our population, smoking prevalence did not differ between the AF and normal cohort $(p=0.84)$. However, smoking prevalence was significantly higher in the rural communities $(\mathrm{p}<0.001)$.
Table 2 Comparison between sinus rhythm and AF subjects at baseline in the REDISCOVER cohort

\begin{tabular}{|c|c|c|c|}
\hline & $\begin{array}{l}\text { Sinus rhythm } \\
N=10752\end{array}$ & $\begin{array}{l}\mathrm{AF} \\
\mathrm{N}=53\end{array}$ & $p$ Value \\
\hline Gender & $\begin{array}{l}\text { Male } 4726(43.9 \%) \\
\text { Female } 6026(56.1 \%)\end{array}$ & $\begin{array}{l}\text { Male } 31(58.5 \%) \\
\text { Female } 22(41.5 \%)\end{array}$ & 0.03 \\
\hline Urban & 5544 & 21 & 0.08 \\
\hline Rural & 5208 & 32 & \\
\hline Ethnicity & & & 0.73 \\
\hline Malay & 7724 & 41 & \\
\hline Chinese & 1155 & 5 & \\
\hline Indian & 313 & 0 & \\
\hline Others & 1560 & 7 & \\
\hline Hypertension & $4891 / 10752$ (45.5\%) & $31 / 53(59.6 \%)$ & 0.04 \\
\hline Ischaemic heart disease & $469 / 10752$ (4.4\%) & $12 / 53(22.6 \%)$ & $<0.001$ \\
\hline Stroke & 138/10 752 (1.3\%) & $1 / 53(1.9 \%)$ & 0.51 \\
\hline Diabetes mellitus & $1788 / 10752(16.6 \%)$ & $13 / 53(24.5 \%)$ & 0.12 \\
\hline Smoking & & & 0.84 \\
\hline Current & $1385 / 10752(12.9 \%)$ & $6 / 53(11.3 \%)$ & \\
\hline Ceased & $1163 / 10752(10.8 \%)$ & $5 / 53(9.4 \%)$ & \\
\hline Non & $8204 / 10752(76.3 \%)$ & $42 / 53(79.3 \%)$ & \\
\hline Death at 3 years & $140 / 10752$ (1.3\%) & $3 / 53(5.7 \%)$ & 0.05 \\
\hline
\end{tabular}

There was a total of three reported deaths $(5.7 \%)$ in the third year follow-up in the AF cohort, compared to 140 deaths $(1.3 \%)$ in the SR cohort, as shown in table 2. All three deaths were attributed to cardiovascular causes, with one death from stroke.

Further multiple regression analysis as shown in table 3 shows that AF itself did not significantly increase the risk of death; however, factors such as increasing age, female gender as well as rural locality carry significantly higher death rates. Associated co-morbidities such as diabetes and ischaemic heart disease are also associated with significantly higher death rates.

Subanalysis of the rural population in REDISCOVER shows significant differences between the prevalence of co-morbidities between these communities compared to the urban population. The prevalence of hypertension, diabetes, ischaemic heart disease and stroke are found to be significantly higher in the rural communities, as shown in table 4.

\section{DISCUSSION}

As evident by multiple community and hospital studies across the world, AF prevalence differs greatly between regions. AF has been found to be more prevalent in Western countries compared to Asian countries. North America has the highest burden of AF, whereas the Asia Pacific region, specifically Japan, Korea and China, has the lowest AF prevalence. A survey of acute medical admissions for AF at a city centre hospital in Birmingham, UK, which serves a multi-ethnic population of 300000 , also indicated that there was a lower prevalence of AF in Indo-Asians compared to Causcasians. ${ }^{28}$ Our communitybased study findings concur with those of other studies in the Asia Pacific regions, with an even lower prevalence of AF.

Factors driving the differences between regions are not clear but could be explained by the following. First, higher detection rates of $\mathrm{AF}$ in Western countries can be due to greater awareness, better diagnostic tools and a more structured healthcare system. Second, diversity in the prevalence of risk factors for 
Table 3 Risk factors associated with death in the REDISCOVER cohort

\begin{tabular}{|c|c|c|c|c|}
\hline & Unadjusted OR (95\% Cl) & p Value & Adjusted OR (95\% CI) & $p$ Value \\
\hline Age & 1.06 (1.05 to 1.08$)$ & $<0.001$ & 1.04 (1.02 to 1.06$)$ & $<0.001$ \\
\hline \multicolumn{5}{|l|}{ Gender } \\
\hline Male & Ref & & Ref & \\
\hline Female & 0.41 (0.29 to 0.57$)$ & $<0.001$ & $0.53(0.36$ to 0.78$)$ & 0.001 \\
\hline $\mathrm{AF}$ & $4.55(1.40$ to 14.76$)$ & 0.012 & $2.39(0.72$ to 7.97$)$ & 0.155 \\
\hline \multicolumn{5}{|l|}{ Geographical area } \\
\hline Urban & Ref & & Ref & \\
\hline Rural & $3.08(2.12$ to 4.49$)$ & $<0.001$ & $2.71(1.85$ to 3.97$)$ & $<0.001$ \\
\hline Hypertension & $1.82(1.30$ to 2.55$)$ & 0.001 & $0.99(0.69$ to 1.42$)$ & 0.944 \\
\hline Ischaemic heart disease & $3.38(2.07$ to 5.53$)$ & $<0.001$ & $2.03(1.21$ to 3.41$)$ & 0.007 \\
\hline Stroke & $1.09(0.27$ to 4.44$)$ & 0.905 & $0.49(0.12$ to 2.06$)$ & 0.336 \\
\hline Diabetes mellitus & 2.57 (1.81 to 3.65$)$ & $<0.001$ & 2.27 (1.58 to 3.27$)$ & $<0.001$ \\
\hline \multicolumn{5}{|l|}{ Smoking } \\
\hline Never & Ref & & Ref & \\
\hline Current & $1.81(1.16$ to 2.81$)$ & 0.009 & $1.18(0.73$ to 1.91$)$ & 0.495 \\
\hline Previous & 2.58 (1.71 to 3.91$)$ & $<0.001$ & $1.48(0.94$ to 2.33$)$ & 0.088 \\
\hline
\end{tabular}

Table 4 Comparison of characteristics and co-morbidities between urban and rural population

\begin{tabular}{lccr}
\hline & $\begin{array}{l}\text { Urban } \\
\mathrm{N}=5565\end{array}$ & $\begin{array}{l}\text { Rural } \\
\mathrm{N}=5240\end{array}$ & p Value \\
\hline Gender & & & \\
$\quad$ Male & $2484(44.6 \%)$ & $2273(43.4 \%)$ & 0.188 \\
$\quad$ Female & $3081(55.4 \%)$ & $2967(56.6 \%)$ & \\
Hypertension & $2354(42.3 \%)$ & $2568(49.0 \%)$ & $<0.001$ \\
Ischaemic heart disease & $211(3.8 \%)$ & $269(5.1 \%)$ & 0.001 \\
Stroke & $59(1.1 \%)$ & $81(1.5 \%)$ & 0.027 \\
Diabetes mellitus & $991(17.8 \%)$ & $810(15.5 \%)$ & 0.001 \\
Smoking & & & \\
$\quad$ Never & $4112(78.3 \%)$ & $3680(72.2 \%)$ & $<0.001$ \\
$\quad$ Current & $564(10.7 \%)$ & $827(16.2 \%)$ & \\
$\quad$ Previous & $579(11.0 \%)$ & $590(11.6 \%)$ & \\
\hline
\end{tabular}

$\mathrm{AF}$, such as ischaemic heart disease, obesity or hypertension, could be responsible for inter-region variability. Cardiovascular diseases such as ischaemic heart disease are now the most prevalent diseases in developed nations, as compared to communicable illnesses in the developing countries. Higher survival rates from myocardial infarction also contribute to the rising trend of $\mathrm{AF}$ prevalence and incidence in Western countries, as $\mathrm{AF}$ is strongly associated with ischaemic heart disease and cardiomyopathy. Finally, differences in the underlying risks resulting from genetic factors might justify this regional heterogeneity.

AF burden in Asia and in Malaysia is expected to increase if the prevalence of predisposing factors such as prior myocardial infarction, heart failure, hypertension, diabetes, valvular disease and obesity increases, as in Western countries. The reason for the discrepancy in the prevalence of AF between Asian and Western countries could then be explained by a time lag in the trends of predisposing factors between Asian and Western countries. In the Prospective Urban Rural Epidemiology (PURE) survey which recruited 160000 adults in 17 countries, ${ }^{29}$ the pooled prevalence of hypertension among the three highincome countries included in the study was $41 \% .{ }^{30}$ In the lower to upper middle income countries, the prevalence of hypertension varied from of $27 \%$ in Iran to $67 \%$ in Poland. ${ }^{30}$ Compared to other cohorts, the prevalence of hypertension in the REDISCOVER population is above the global prevalence and that of high income countries. This inevitably will lead to increases in cardiovascular related morbidity and mortality, including a rising trend in $\mathrm{AF}$ in years to come.

In our study, there was a trend towards a significant difference in AF prevalence between rural and urban populations, with $\mathrm{AF}$ being more prevalent in the rural populations. This can be explained by the significantly higher prevalence of its associated risk factors such as hypertension, stroke, smoking and ischaemic heart disease observed in the rural communities. The possible explanation for our finding is that the rural population in Malaysia has limited access to healthcare, and thus poorer awareness, control and optimisation of their cardiovascular risk factors. Hence this population group is at a higher risk of cardiovascular-related illnesses. However, in terms of racial differences, we found that there was no difference in AF prevalence between different ethnic groups in the Malaysia population.

The prevalence of AF in our cohort is lower than that found in a previous local study in a group of hypertensive patients in Sarawak $(0.75 \%$ vs $0.54 \%) .^{25}$ This can be explained by the higher prevalence of hypertension in that group. In a large community study from Korea, a higher prevalence of $0.7 \%$ is seen across the cohort. ${ }^{17}$ This is mainly driven by a higher rate of AF in the older age group ( $4 \%$ in those subjects $>80$ years old). ${ }^{17}$

Despite being an epidemiological study, our follow-up rate is satisfactory at $90 \%$ with a low fallout rate. The limitation of our study is under-reporting of chronic illnesses in the interview-based questionnaires and inter-observer variability in questionnaire completion. This will undoubtedly result in underestimation of the prevalence of chronic illnesses.

\section{CONCLUSION}

Our study found an overall prevalence of AF of $0.54 \%$, which is lower than the global average of $1 \%$. The most likely explanation for our finding is the lower burden of cardiovascular disease as well as a population cohort that is younger on 
average, with a mean age of 53 years. In our study, AF was found to be more prevalent in males, and its prevalence increased with age. It was also associated with ischaemic heart disease and hypertension. Global burden of AF is predicted to rise in years to come and with the urbanisation in the Asian countries, we may soon see a trend similar to that in developed nations. Physicians in Singapore and Malaysia report that AF patient numbers have increased by approximately $10 \%$ over the last 3 years and will continue to rise. ${ }^{31}$ AF will continue to pose a major burden to the public health cost in years to come with its associated morbidity and mortality.

Twitter Follow Johan Rizwal Ismail at @johanrizwal

Acknowledgements The authors acknowledge the following REDISCOVER Investigators for their contributions towards the study: Fadhlina Abdul Majid, Najmin Abu Bakar, Mohd Yazrie Yacob, Rafezah Razali, Razif Dasiman, Rosiah Ahmad, Sarina Ali and Tengku Saifudin Tengku Ismail. The authors also extend their appreciation to all participants and staff of the Faculty of Medicine, Universiti Teknologi MARA, for their contributions.

Contributors CWL and SK wrote the manuscript and were involved in the data collection of the REDISCOVER Study. JRI performed the statistical analysis and contributed to the critical discussion of the results. NCYC, RNK, EAR, MKMA, HAZA and $\mathrm{ZIO}$ contributed to the critical revision of the manuscript and were involved in the data collection. $\mathrm{KY}$ is the Principal Investigator of this study. He played a major role in the conception and design of the study, contributed to the critical revision of the manuscript and intellectual content, and provided expertise and oversight throughout the process. All authors read and approved the final version.

Funding Ministry of Higher Education and Ministry of Science, Technology and Innovation Malaysia.

Competing interests None declared.

Participant consent Obtained.

Ethics approval Institutional Ethics Committee.

Provenance and peer review Not commissioned; externally peer reviewed.

\section{REFERENCES}

1 Chugh SS, Havmoeller R, Narayanan K, et al. Worldwide epidemiology of atrial fibrillation: a global burden of disease 2010 study. Circulation 2014;129:837-47.

2 Wolf PA, Benjamin EJ, Belanger AJ, et al. Secular trends in the prevalence of atrial fibrillation: the Framingham study. Am Heart J 1996;131:790-5.

3 Go AS, Hylek EM, Phillips KA, et al. Prevalence of diagnosed atrial fibrillation in adults: national implications for rhythm management and stroke prevention: the AnTicoagulation and Risk Factors in Atrial Fibrillation (ATRIA) Study. JAMA 2001;285:2370-5.

4 Davis RC, Hobbs FD, Kenkre JE, et al. Prevalence of atrial fibrillation in the general population and in high-risk groups: The ECHOES study. Europace 2012;14:1553-9.

5 Stewart S, Hart CL, Hole DJ, et al. Population prevalence, incidence, and predictors of atrial fibrillation in the Renfrew/Paisley study. Heart 2001;86:516-21.

6 Heeringa J, van der Kuip DA, Hofman A, et al. Prevalence, incidence and lifetime risk of atrial fibrillation: the Rotterdam study. Eur Heart J 2006;27:949-95.

7 Ball J, Thompson DR, Ski CF, et al. Estimating the current and future prevalence of atrial fibrillation in the Australian adult population. Med J Aust 2015;202:32-5.

8 Kitamura A, Shimamoto T, Doi M, et al. Secular trends in prevalence and incidence of atrial fibrillation and associated factors in a Japanese rural population. Jpn J Public Health 1991;38:95-105.
9 Ohsawa M, Okayama A, Sakata K, et al. Rapid increase in estimated number of persons with atrial fibrillation in Japan: an analysis from national surveys on cardiovascular diseases in 1980, 1990 and 2000. J Epidemio/ 2005;15:194-6.

10 Inoue $\mathrm{H}$, Fujiki $\mathrm{A}$, Origasa $\mathrm{H}$, et al. Prevalence of atrial fibrillation in the general population of Japan: an analysis based on periodic health examination. Int J Cardiol 2009:137:102-7.

11 Iguchi Y, Kimura K, Aoki J, et al. Prevalence of atrial fibrillation in community-dwelling Japanese aged 40 years or older in Japan: analysis of 41,436 non-employee residents in Kurashiki-city. Circ J 2008;72:909-13.

12 Nakamura $\mathrm{M}$, Endo $\mathrm{H}$, Nasu $\mathrm{M}$, et al. Value of plasma B type natriuretic peptide measurement for heart disease screening in a Japanese population. Heart 2002:87:131-5.

13 Ohsawa M, Okayama A, Okamura T, et al. Mortality risk attributable to atrial fibrillation in middle-aged and elderly people in the Japanese general population: nineteen-year follow-up in NIPPON DATA80. Circ J 2007;71:814-19.

14 Ohsawa M, Itai K, Tanno K, et al. Cardiovascular risk factors in the Japanese north-eastern rural population. Int J Cardiol 2009;137:226-35.

15 Uchiyama S, Shibata Y, Hirabayashi T, et al., J-TRACE Investigators. Risk factor profiles of stroke, myocardial infarction, and atrial fibrillation: a Japanese multicenter cooperative registry. J Stroke Cerebrovasc Dis 2010;19:190-7.

16 Watanabe H, Tanabe N, Watanabe T, et al. Metabolic syndrome and risk of development of atrial fibrillation: the Niigata preventive medicine study. Circulation 2008;117:1255-60.

17 Jeong JH. Prevalence of and risk factors for atrial fibrillation in Korean adults older than 40 years. J Korean Med Sci 2005;20:26-30.

$18 \mathrm{Mu}$ HY, Qiu P, Lu WH, et al. Electrocardiogram Minnesota codings from 30000 adult cases with Kazakh ethnicity in Xinjiang, China. Zhonghua Liu Xing Bing Xue Za Zhi 2010;31:451-4.

19 Long MJ, Jiang CQ, Lam TH, et al. Atrial fibrillation and obesity among older Chinese: the Guangzhou Biobank Cohort Study. Int J Cardiol 2011;148:48-52.

20 Zhang $X$, Zhang S, Li Y, et al. Association of obesity and atrial fibrillation among middle-aged and elderly Chinese. Int J Obes (Lond) 2009;33:1318-25.

21 Zhou Z, Hu D. An epidemiological study on the prevalence of atrial fibrillation in the Chinese population of mainland China. J Epidemiol 2008;18:209-16.

22 Assantachai P, Panchavinnin P, Pisalsarakij D. An electrocardiographic survey of elderly Thai people in the rural community. J Med Assoc Thai 2002;85:1273-9.

23 Kiatchoosakun S, Pachirat O, Chirawatkul A, et al. Prevalence of cardiac arrhythmias in Thai community. J Med Assoc Thai 1999:82:727-33.

24 Yap KB, Ng TP, Ong HY. Low prevalence of atrial fibrillation in community-dwelling Chinese aged 55 years or older in Singapore: a population-based study. J Electrocardiol 2008:41:94-8.

25 Wong JS, Bau R, Ahmad F, et al. Prevalence of asymptomatic atrial fibrillation in Malaysian patients with hypertension. Med J Malaysia 2013:68:141-3

26 Freestone $B$, Rajaratnam $\mathrm{R}$, Hussain $\mathrm{N}$, et al. Admissions with atrial fibrillation in a multiracial population in Kuala Lumpur, Malaysia. Int J Cardiol 2003;91:233-8.

27 Ramli AS, Mohammad Daher A, Nor-Ashikin MN, et al. JIS definition identified more Malaysian adults with metabolic syndrome compared to the NCEP-ATP III and IDF criteria. Biomed Res Int 2013:2013:760963.

28 Zarifis J, Beevers G, Lip GY. Acute admissions with atrial fibrillation in a British multiracial hospital population. Br J Clin Pract 1997:51:91-6.

29 Teo K, Chow CK, Vaz M, et al., PURE Investigators- Writing Group. The Prospective Urban Rural Epidemiology (PURE) study: examining the impact of societal influences on chronic noncommunicable diseases in low-, middle-, and high-income countries. Am Heart J 2009;158:1-7.e1.

30 Chow CK, Teo KK, Rangarajan S, et al., PURE (Prospective Urban Rural Epidemiology) Study Investigators. Prevalence, awareness, treatment, and control of hypertension in rural and urban communities in high-, middle-, and low-income countries. JAMA 2013;310:959-68.

31 Omar R, Teo WS, Foo D, et al. Atrial fibrillation in Singapore and Malaysia: current trends and future prospects. J Arrhythmia 2011;27:171-85. 